\title{
Aftershock observation of the 2003 Tokachi-oki earthquake by using dense ocean bottom seismometer network
}

\author{
Masanao Shinohara ${ }^{1}$, Tomoaki Yamada ${ }^{1}$, Toshihiko Kanazawa ${ }^{1}$, Naoshi Hirata ${ }^{1}$, Yoshiyuki Kaneda ${ }^{2}$, Tetsuo Takanami ${ }^{3}$, \\ Hitoshi Mikada ${ }^{2}$, Kiyoshi Suyehiro ${ }^{2}$, Shin'ichi Sakai ${ }^{1}$, Tomoki Watanabe ${ }^{2}$, Kenji Uehira $^{4}$, Yoshio Murai ${ }^{3}$, \\ Narumi Takahashi ${ }^{2}$, Minoru Nishino ${ }^{5}$, Kimihiro Mochizuki ${ }^{1}$, Takeshi Sato ${ }^{2}$, Ei'ichiro Araki ${ }^{2}$, \\ Ryota Hino ${ }^{5}$, Kouichi Uhira ${ }^{6}$, Hajime Shiobara ${ }^{1}$, and Hiroshi Shimizu ${ }^{4}$ \\ ${ }^{1}$ Earthquake Research Institute, University of Tokyo, Tokyo 113-0032, Japan \\ ${ }^{2}$ Japan Marine Science and Technology Center, Yokosuka 237-0061, Japan \\ ${ }^{3}$ Institute of Seismology and Volcanology, Hokkaido University, Sapporo 060-0810, Japan \\ ${ }^{4}$ Institute of Seismology and Volcanology, Kyushu University, Shimabara 855-0843, Japan \\ ${ }^{5}$ Graduate School of Science, Tohoku University, Sendai 980-8578, Japan \\ ${ }^{6}$ Japan Meteorological Agency, Tokyo 100-8122, Japan
}

(Received December 5, 2003; Revised March 5, 2004; Accepted March 5, 2004)

\begin{abstract}
The Tokachi-Oki earthquake occurred on September 26, 2003. Precise aftershock distribution is important to understand the mechanism of this earthquake generation. To study the aftershock activity, we deployed fortyseven ocean bottom seismometers (OBSs) and two ocean bottom pressure meters (OBPs) at thirty-eight sites in the source region. We started the OBS observation four days after the mainshock for an observation period of approximately two months. In the middle of the observation period, nine OBSs near the epicenter of the mainshock were recovered to clarify the depth distribution of aftershocks near the mainshock. From the data overall OBS, seventy-four aftershocks were located with high spatial resolution. Most of the aftershocks were located in a depth range of 15-20 km and occurred within the subducting oceanic crust, the $5.5-\mathrm{km} / \mathrm{s}$ layer of the landward plate and the plate boundary. No aftershocks were found in the mantle of the subducting plate. The low seismic activity beneath the trench area where the water depth is greater than about $2000 \mathrm{~m}$ suggests a weak coupling between the two plates. The depth of the mainshock is inferred to be $15-20 \mathrm{~km}$ from the aftershock distribution.
\end{abstract}

Key words: The 2003 Tokachi-oki earthquake, aftershock, subduction, ocean bottom seismometer (OBS).

\section{Introduction}

The Tokachi-Oki earthquake $(M=8.0)$ occurred offshore of Tokachi region, Hokkaido, Japan, on September 26, 2003. Many aftershocks occurred following the mainshock, the largest of magnitude $M=7.1$ on September 26, 2003. The source region of this earthquake is considered to be the same as that of the previous Tokachi-oki earthquake $(M=8.2)$ which occurred on March 4, 1952 (Yamanaka and Kikuchi, 2003). The new earthquake is estimated to be located at the plate boundary between the subducting Pacific plate and the landward plate. Knowledge of precise aftershock distribution is important to understand the mechanism of earthquake generation. In addition, this kind of information is useful for studies of earthquake prediction in other trench areas. Previous studies indicate that ocean bottom seismometer (OBS) observation is essential to obtain a high resolution aftershock distribution for large earthquakes which occurred in marine areas (e.g. Hino et al., 2000; Urabe et al., 1985).

In 1999, three OBSs and two tsunami meters were deployed off Kushiro and Tokachi in the Kuril Trench region by Japan Marine Science and Technology Center (Hirata et al., 2002). These sensors are connected by an ocean bottom

Copy right(c) The Society of Geomagnetism and Earth, Planetary and Space Science (SGEPSS); The Seismological Society of Japan; The Volcanological Society of Japan The Geodetic Society of Japan; The Japanese Society for Planetary Sciences; TERRAPUB cable and their data are transmitted to a land in real-time. The cabled OBSs recorded the 2003 mainshock and many aftershocks. The data from the cabled OBSs contribute to the improvement of the hypocenter location in the source region. However, the cabled OBS network has large instrument intervals of more than $30 \mathrm{~km}$. To reveal precise aftershock distribution, a spatially dense OBS network covering the source region is needed.

Four days after the mainshock, we started an aftershock observation using pop-up type OBSs in order to obtain the detailed aftershock activity of the 2003 Tokachi-oki earthquake. In the middle of the observation period, a portion of the OBS array was recovered and other OBSs were deployed at the same position. In addition, ten OBSs were deployed at additional positions in the middle of the observation period. Therefore we deployed a total of forty-seven OBSs and two ocean bottom pressure meters (OBPs) at thirty-eight sites in the source region of the mainshock. After three weeks from the first deployment, we retrieved nine OBSs in the southwestern part of the OBS network in order to obtain a detailed aftershock distribution, especially depth distribution in the mainshock region. For studies of the mainshock, its precise aftershock distribution in the mainshock region is important and should be needed at early stages of other studies. This paper focuses on the description of the OBS observation and the precise aftershock distribution, with an emphasis on 


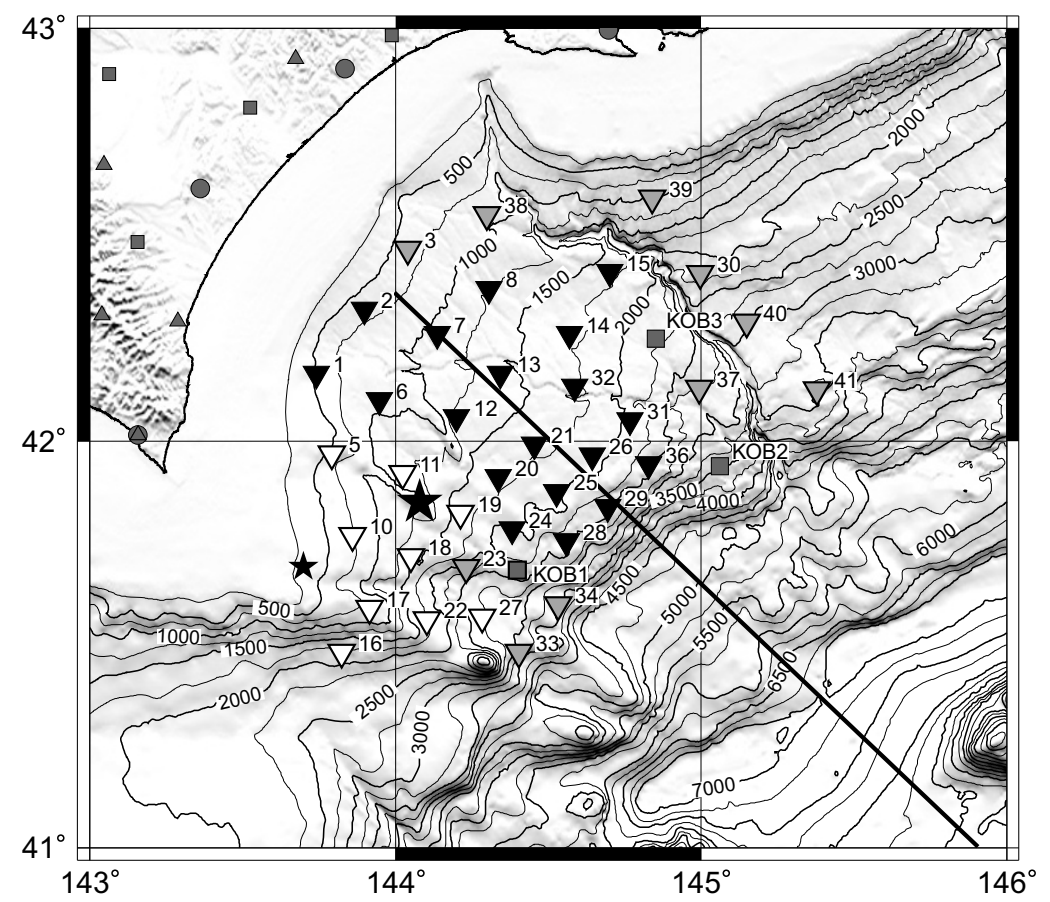

Fig. 1. Location map of ocean bottom seismometers with bathymetric features. Inverted triangles indicate the positions of pop-up type OBSs and OBPs. Solid inverted triangles indicate the positions of the OBSs which were deployed through the whole observation period. Open inverted triangles and inverted triangles filled by gray denote the positions of OBS used for this study and the positions of the OBSs deployed in mid-October, 2003, respectively. Squares indicate the positions of the cabled OBSs. Numerals indicate site number. OBPs were deployed at sites 8 and 36 . Gray symbols in land region show the positions of the permanent seismic stations. Large and small stars indicate the epicenters of the mainshock and the largest aftershock, respectively. Thick line indicates the profile of the seismic survey using OBSs in 1983 (Iwasaki et al., 1989).

Table 1. Summary of observation period of each site. Arrows indicate the period of observation data. Gray arrow shows the period of OBS data for this study.

\begin{tabular}{|c|c|c|}
\hline Sites & First period (Sep. 30 - Oct. 21) & Second period (Oct. 22 - Nov. 20) \\
\hline $\begin{array}{l}1,2,6,7,8,12,13,14,15,20, \\
21,24,25,26,28,29,31,32,\end{array}$ & \multicolumn{2}{|c|}{ Continuous observation through the whole period } \\
\hline $5,10,11,16,17,18,19,22,27$ & \multicolumn{2}{|c|}{ Replacement of OBSs } \\
\hline & Data for this study & Except for site 16 \\
\hline $\begin{array}{l}3,23,30,33,34,37,38,39,40, \\
41\end{array}$ & & Additional observation \\
\hline Total number of stations & 31 & 40 \\
\hline
\end{tabular}

depths of events, using the nine OBSs that were recovered after three weeks of the first deployment plus one cabled OBS in the southwestern part of the source region. In the future, the precise aftershock distribution in the whole observation area will be determined using data from all the OBSs.

\section{Observation}

Four days after the 2003 Tokachi-oki earthquake, we started to deploy twenty-nine OBS in the source region using the M/V Shinryu-maru (Shin Nippon Kaiji Co., chartered by Earthquake Research Institute, University of Tokyo) in order to study the aftershock activity of this event. From October 19 to 21,2003 , nine OBSs which had been deployed near the epicenter of the mainshock were recovered by R/V Natsushima belonging to the Japan Marine Science and Technology Center (JAMSTEC). Unfortunately, one OBS could not be recovered. We deployed eleven OBSs in order to continue the aftershock observation. On October 18 and 19, seven OBSs were additionally deployed by the R/V Kofu- maru, (the Japan Meteorological Agency (JMA)) in order to enlarge the observation area. Two ocean bottom pressure meters (OBPs) were also deployed by the R/V Kofu-maru in order to detect vertical crustal movement east of the source region where large slip is estimated (Yamanaka and Kikuchi, 2003). Consequently, we observed aftershocks at forty-one sites including the three cabled OBS sites (Fig. 1). All the OBSs and OBPs at the sea floor were recovered by M/V Shintatsu-maru, chartered by ERI, University of Tokyo, from November 17 to 20. The observation periods of each site are summarized in Table 1. The observation area is $150 \mathrm{~km} \times$ $100 \mathrm{~km}$ and has a high aftershock activity, which is estimated from the land seismic network. The OBS interval is approximately $15 \mathrm{~km}$ in the trench region. In the near-shore area, OBSs were deployed at an interval of about $20 \mathrm{~km}$ because the aftershocks are estimated to occur in the deeper region.

We used two types of digital recording OBS systems. Forty-six OBSs had both vertical and horizontal velocity sensitive electro-magnetic geophones with a natural frequency 


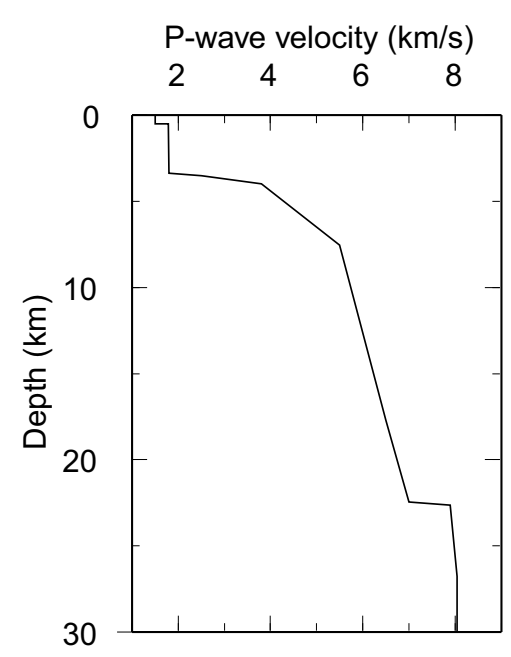

Fig. 2. $P$-wave velocity structure model for the hypocenter determination. The model is derived from the refraction experiment carried out using the OBSs in 1983 (Iwasaki et al., 1989).

of $4.5 \mathrm{~Hz}$, one OBS used a three-component broadband seismic sensor (Guralp CMG-3T), and nine OBSs used for this study had short-period seismometers. Accurate timing, estimated to be within $0.05 \mathrm{~s}$ for the whole observation period, is provided by a crystal oscillator. OBS positions at the sea floor were obtained using acoustic ranging and ship GPS positions, and their accuracy is estimated to be several meters by a location program. We also determined the water depth to the OBSs by acoustic ranging.

\section{Data and Hypocenter Determination}

We used waveform data from nine pop-up type OBSs recovered by the R/V Natsushima from October 19 to 21, 2003 and one cabled OBS (KOB1). These pop-up type OBSs have a recording period of approximately three weeks and were deployed close to the epicenter of the mainshock. For analysis, we selected events using the method of short-term and long-term averages of seismic signal amplitude from the cabled OBSs and the land seismic stations near the observation area (Ambuter and Solomon, 1974). More than four-hundred events were detected by this event detection method. All OBS data were combined into multistation waveform data files for each event. $P$ and $S$ wave arrival times were picked on a computer display (Urabe and Tsukada, 1991). Four hundred eighty events recorded by more than three OBSs were selected for hypocenter determinations.

Extensive seismic experiments were carried out in 1983 in the study area using controlled seismic sources and OBSs in order to obtain a detailed seismic structure (Iwasaki et al., 1989). Although the aftershock area has large lateral heterogeneity in seismic structure due to plate subduction, because of the relatively small study area, a simple one dimensional seismic wave velocity structure for the hypocenter location was obtained from the results of the refraction study (Iwasaki et al., 1989). We used the seismic structure just below station S6 in Iwasaki et al. (1989). $P$-wave velocities from $1.8 \mathrm{~km} / \mathrm{s}$ to $3.8 \mathrm{~km} / \mathrm{s}$ are interpreted by Iwasaki et al. (1989) to be the sedimentary layer of the landward plate, and $P$-wave velocities from $3.8 \mathrm{~km} / \mathrm{s}$ to $5.5 \mathrm{~km} / \mathrm{s}$ are the upper crustal layer in
Table 2. Summary of residuals of travel times for each site. O-C: averaged residual between observed travel times and estimated travel times, SC: station correction, RMS: root mean square of O-C with station correction.

\begin{tabular}{rcccccc} 
Station & \multicolumn{3}{c}{ P-waves } & \multicolumn{3}{c}{ S-waves } \\
\hline $\begin{array}{c}\text { O-C (s) } \\
\text { without SC }\end{array}$ & $\begin{array}{c}\text { O-C (s) } \\
\text { with SC }\end{array}$ & RMS (ms) & $\begin{array}{c}\text { O-C (s) } \\
\text { without SC }\end{array}$ & $\begin{array}{c}\text { O-C (s) } \\
\text { with SC }\end{array}$ & RMS (ms) \\
\hline Site5 & -0.393 & 0.116 & 62.8 & 0.745 & 0.245 & 83.9 \\
Site10 & -0.463 & 0.050 & 0.4 & 1.012 & 0.055 & 77.4 \\
Site11 & 0.088 & 0.069 & 3.5 & 1.873 & 0.074 & 61.4 \\
Site16 & 0.497 & 0.012 & 9.5 & 3.207 & 0.040 & 64.5 \\
Site17 & -0.053 & 0.006 & 14.2 & 1.916 & 0.024 & 117.5 \\
Site18 & -0.444 & -0.013 & 33.3 & 0.822 & -0.029 & 212.1 \\
Site19 & -0.060 & -0.018 & 15.4 & 1.700 & -0.008 & 66.5 \\
Site22 & 0.270 & -0.023 & 37.4 & 3.203 & -0.328 & 90.2 \\
Site27 & 0.458 & -0.071 & 40.1 & 4.182 & -0.074 & 56.1 \\
KOB1 & -0.060 & -0.092 & 75.3 & 1.700 & -0.147 & 197.8 \\
\hline & & & & & &
\end{tabular}

the landward plate. The thicknesses of these two layers in the landward plate are $2 \mathrm{~km}$ and $3.5 \mathrm{~km}$, respectively. The third layer has $P$-wave velocities of $5.5 \mathrm{~km} / \mathrm{s}$ to $7.0 \mathrm{~km} / \mathrm{s}$ with a thickness of $10 \mathrm{~km}$. The $P n$ velocity is $7.9 \mathrm{~km} / \mathrm{s}$ (Fig. 2). We also assumed that the ratio of $P$-wave to $S$-wave velocity in the crust and mantle is 1.73 , because $S$ wave structure is not determined by Iwasaki et al. (1989). Since the thickness of sedimentary layers changes at each OBS site, the estimated travel times by the location program must be corrected.

Hypocenters were determined by a maximum-likelihood estimation technique of Hirata and Matsu'ura (1987). Due to uncertainty in the thickness and velocity of the sedimentary layer, we used the following method. First, we located the hypocenter using $P$ and $S$ wave arrival times without correction values for the sedimentary layer. Averaged differences between observed travel times and estimated travel times (O$\mathrm{C}$ times) were calculated for each OBS. Next we located the hypocenter using the averaged $\mathrm{O}-\mathrm{C}$ times as correction values. A new set of averaged O-C times for each OBS were calculated from the results of the second locations. Finally the new averaged $\mathrm{O}-\mathrm{C}$ times were added to the previous correction values, and the hypocenters were again relocated. We repeated the relocation process using the last procedure two times. At the end of this analysis, the averaged $\mathrm{O}-\mathrm{C}$ times become approximately $0.1 \mathrm{~s}$ and $0.2 \mathrm{~s}$ for $P$-wave and $S$ wave, respectively (Table 2). Magnitudes of the aftershocks were estimated using the maximum amplitude of the seismic record on the land (Watanabe, 1971).

\section{Results}

Among 480 detected events, 395 events were able to be located. We selected the events with the criteria of small spatial errors and more than one $S$-wave reading from the OBS network. The OBS network located seventy-four earthquakes with an error of less than $1 \mathrm{~km}$ in the horizontal direction and less than $3 \mathrm{~km}$ in depth (Fig. 3). The estimation errors of each aftershock location were calculated from the total covarience matrix of the location program (Hirata and Matsu'uura, 1987). Magnitudes of these 74 aftershocks range from 1.7 to 5.2. The epicenters of these aftershocks are limited to within the OBS network used in this study. In other words, the resolution of hypocenters is considerably high within the OBS network.

The epicenter distribution is not uniform. The aftershocks may be divided into spatial clusters. We can identify at least 


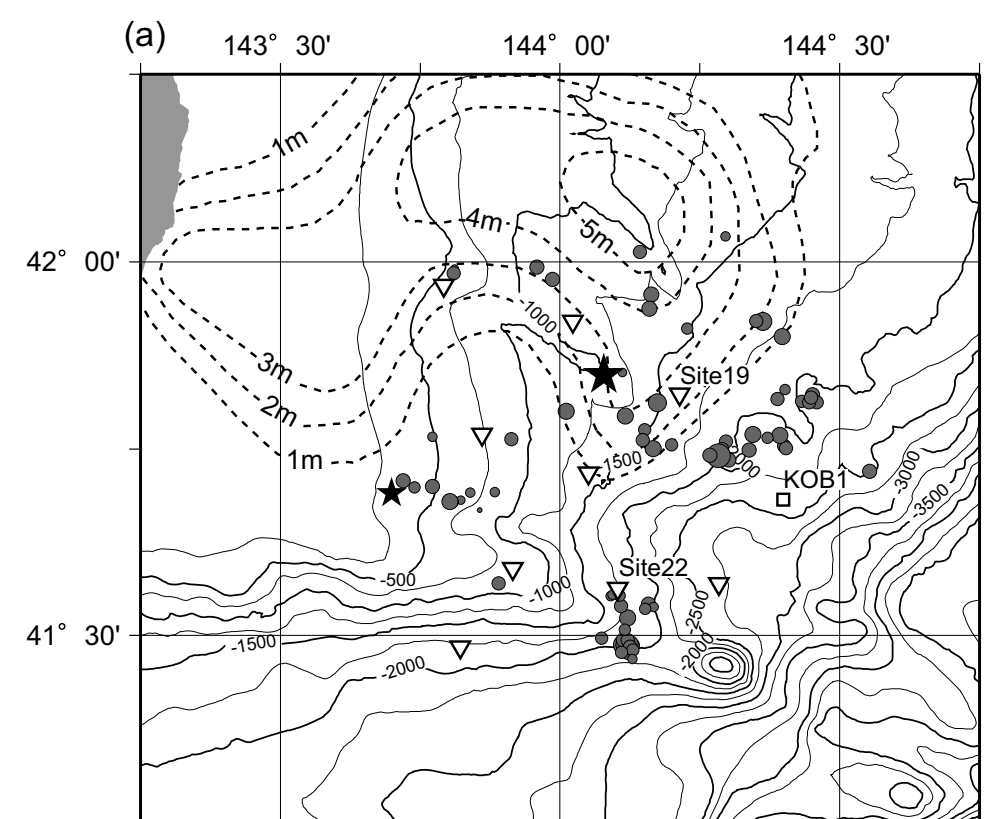

(b)

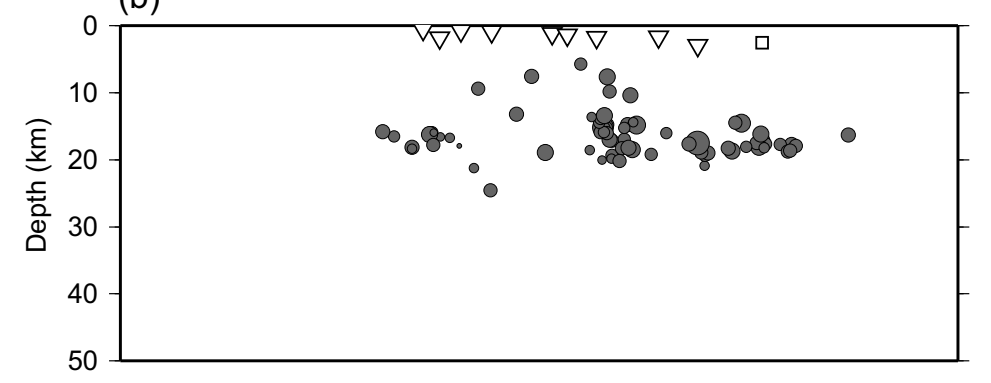

(c)

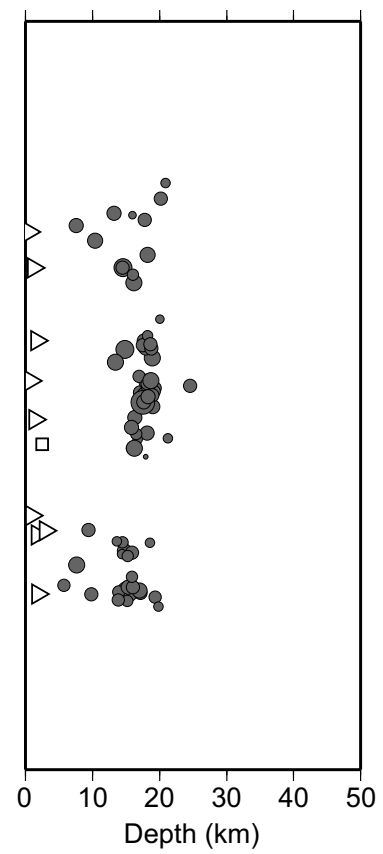

$M=6$

- $M=4$

- $M=2$

- UND

$\mathrm{N}=74$

Fig. 3. Hypocenter distribution (October 1st-October 20th, 2003) with bathymetry (a). The inverted triangles and the square indicate positions of the pop-up type OBSs and the cabled OBS, respectively. The gray circles represent hypocenters. Diameters of the circles are proportional to magnitudes. Contours drawn by dash lines show the fault slip of the mainshock estimated by telseismic body waves (Yamanaka and Kikuchi, 2003). E-W vertical cross section (b) and N-S vertical cross section (c). Aftershocks with an error of less than $1 \mathrm{~km}$ for the horizontal direction and less than $3 \mathrm{~km}$ in depth are plotted. In the vertical section, concentration of the aftershocks in depths of $15-20 \mathrm{~km}$ is clearly recognized.

two clusters near Site 22 and between KOB1 and Site 19. In the study area, most of the aftershocks are located in a depth range of 15-20 km. Aftershocks beneath the island arc slope are frequent, but in contrast there is low seismic activity beneath the landward slope where the water depth is greater than about $2000 \mathrm{~m}$. No hypocenters were detected with depths greater than $30 \mathrm{~km}$.

\section{Discussion}

Among our 74 hypocenters, 20 hypocenters correspond to those determined by JMA from the land seismic network. We compare our results to those by the JMA (Fig. 4). Although most JMA hypocenters, which include the data from the cabled OBSs, have depths of greater than $20 \mathrm{~km}$, all hypocenters determined by our OBS network have focal depths around $20 \mathrm{~km}$. From the principle of locating hypocenters, the use of $P$ and $S$ wave arrivals at seismic stations above a hypocenter is essential in order to obtain precise hypocenter position, especially for its depth. Our OBS network satisfies this condition and this has high resolution for the determination of event depth. All hypocenters by the OBS network were determined to be shallower than those by JMA. Most of the aftershocks are concentrated around a horizontal plane at a depth of approximately $20 \mathrm{~km}$. This seismic plane as formed by the aftershocks can be interpreted to be the fault zone of the mainshock. Therefore the depth of the mainshock is inferred to be around $20 \mathrm{~km}$. In addition, we compared $P$-wave arrival times at the land stations for aftershocks shown in Fig. 4 to those for the mainshock. According to uncertainty of origin times of the events, we used differences of the arrival times for every pair at the land stations. The aftershocks whose epicenters were close to that of the mainshock have small differences compared to the difference for the mainshock. This means that the depth of the mainshock may be similar to that of aftershocks estimated by the OBS network, and it is difficult to estimate a precise depth of the mainshock from the land seismic network.

In a cross section of the hypocentral distribution projected on a vertical plane along the seismic survey (Iwasaki et al., 1989), we can clearly see the relation between the aftershock distribution and the seismic velocity structure (Fig. 5). The seventy-four aftershocks we could locate occurred within the plate boundary, the subducting oceanic crust and the 5.5$\mathrm{km} / \mathrm{s}$ layer in the landward plate. Most of these aftershocks seem to be concentrated within the subducting oceanic crust. The velocity structure from the seismic survey shows that the 


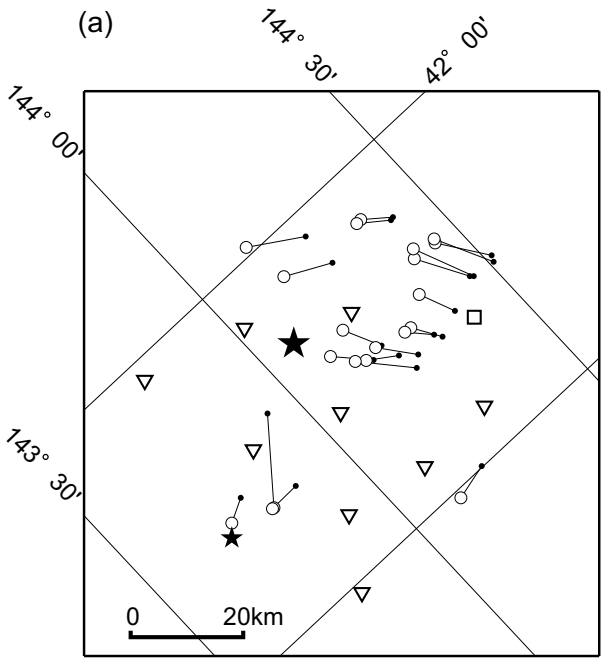

(b)

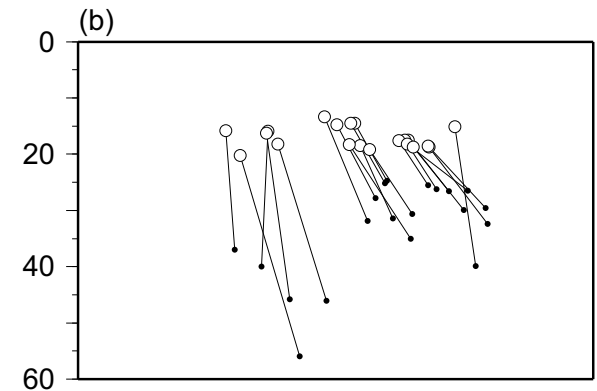

(c)

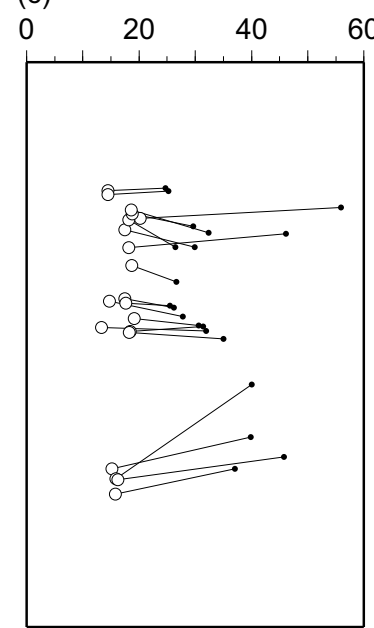

This study

- JMA

Fig. 4. Comparison between hypocenters by the OBS networks (open circles) and those determined by the JMA (dots). The inverted triangles and the square indicate positions of the pop-up type OBSs and the cabled OBS, respectively. Stars indicate the epicenters of the mainshock and the largest aftershock.

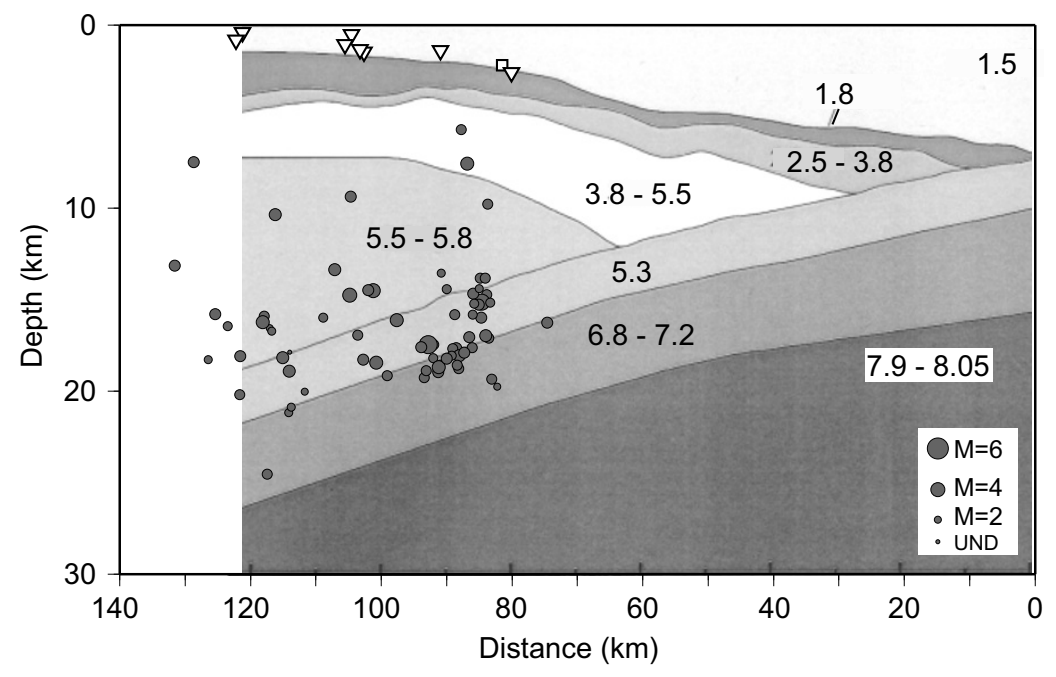

Fig. 5. Vertical section of $P$-wave velocity structure and the aftershock distribution along the refraction profile (Iwasaki $e t$ al., 1989). The profile of the refraction survey (thick line in Fig. 1) is perpendicular to the strike of the trench. Gray circles indicate the hypocenters of the aftershocks, and diameters of circles correspond to magnitudes. Inverted triangles and square indicated the projected position of the pop-up type OBSs and the cabled OBS, respectively. Numerals denote $P$-wave velocities $(\mathrm{km} / \mathrm{s})$. Distance in horizontal axis is measured from the trench axis.

upper layer in the subducting plate has lower velocity than that in the overlying layer. However, this low velocity layer is not taken into account during the hypocenter determination. Our simplified velocity model should affect aftershock location in that their foci are determined to be deeper than their actual depths. Therefore, there is a possibility that the concentration of the aftershocks occurs at the plate boundary between the Pacific plate and the overlying landward plate. Finally, we found no aftershock in the mantle of the subducting Pacific plate.

Although our OBS data show high seismicity around the plate boundary, a few aftershocks were located beneath the landward slope where the water depth is greater than about $2000 \mathrm{~m}$. Because the boundary between the high seismicity 
region and a low seismicity area is positioned within the OBS network used in this study, there is a possibility that a low seismic area extends $80 \mathrm{~km}$ inward from the Kuril trench axis. Low seismic activity along the plate boundary implies that there is a weak coupling between the Pacific plate and the landward plate from the trench axis to $80 \mathrm{~km}$ landward. Such aseismic areas are found close to the Japan trench and the Nankai trough in background seismicity (Hirata et al., 1985; Obana et al., 2001).

Yamanaka and Kikuchi (2003) investigated the source rupture processes of the 2003 event using teleseismic $P$ - and $S H$-waves data. The maximum dislocation is estimated to be $5.5 \mathrm{~m}$ and the rupture of the mainshock propagated northward from shallow to deeper levels. Although our OBS network in this study covered only a part of the slip region estimated by Yamanaka and Kikuchi (2003), more aftershocks seems to occur outside of the large slip region. This tendency corresponds with the asperity hypothesis of Yamanaka and Kikuchi (2004). Because our aftershock distribution is limited, we need to analyze the aftershock distribution of the whole source area of the 2003 Tokachi-oki earthquake using the whole OBS network in order to confirm their hypothesis.

\section{Conclusions}

In order to obtain precise aftershock distribution of the 2003 Tokachi-oki Earthquake, forty-seven OBSs and two OBPs were deployed at thirty-eight sites from September 30 to November 20, 2003, in the source region of the mainshock. Nine OBSs deployed near the epicenter of the mainshock in the southwestern area of the whole OBS network were recovered after three weeks from the mainshock. In this study, we presented obtained locations of seventy-four aftershocks near the mainshock with high spatial resolution during the observation period using the nine OBSs. Most of aftershocks are located in a depth range of $15-20 \mathrm{~km}$. No earthquakes are observed in the mantle of the subducting Pacific plate. The seismicity is higher beneath the slope on the island arc side, and there is a possibility of low seismic activity beneath the landward slope where the water depth is greater than about $2000 \mathrm{~m}$. In a vertical cross section of the hypocentral distribution, the aftershocks concentrate in the plate boundary region of the subducting Pacific plate and the overlying landward plate. From the depth distribution of the aftershocks near the mainshock, we infer that the mainshock has a depth of $15-20 \mathrm{~km}$.

Acknowledgments. We express thanks to Messrs. M. Ito, I. Terada, and Ms. M. Hori for helps in the OBS observation on board. The work of the officers and crew of M/V Shinryu-maru, R/V
Natsushima, R/V Kofu-maru and M/V Shintatsu-maru is appreciated. We also thank many students of universities for preparation of the OBS observation, Ms. R. Otsuka for the OBS data processing, and Drs. D. Okaya and T. L. Wright for critical reading of the manuscript. Comments by Dr. A. Nishizawa and an anonymous reviewer helped us improve the manuscript. This study is partly supported by the Special Coordination Funds for the Promotion of Science and Technology (MEXT, Japan) titled as the Urgent Research for the 2003 Tokachi-oki Earthquake. Most of the figures were created using GMT (Wessel and Smith, 1995).

\section{References}

Ambuter, B. P. and S. C. Solomon, An event recording system for monitoring small earthquakes, Bull. Seismol. Soc. Am., 64, 1181-1188, 1974.

Hino, R., S. Ito, H. Shiobara, H. Shimamura, T. Sato, T. Kanazawa, J. Kasahara, and A. Hasegawa, Aftershock distribution of the 1994 Sanriku-oki earthquake (Mw 7.7) revealed by ocean bottom seismographic observation, J. Geophys. Res., 105, 21697-21710, 2000.

Hirata, K., M. Aoyagi, H. Mikada, K. Kawaguchi, Y. Kaiho, R. Iwase, S. Morita, I. Fujisawa, H. Sugioka, K. Mitsuzawa, K. Suyehiro, H. Kinoshita, and N. Fujiwara, Real-time geophysical measurements on the deep seafloor using submarine cable in the southern Kuril subduction zone, IEEE Journal of Oceanic Engineering, 27, 2, 170-181, 2002.

Hirata, N., T. Kanazawa, K. Suyehiro, and H. Shimamura, H., A seismicity gap beneath the inner trench wall of the Japan Trench as derived by ocean bottom seismograph measurement, Tectonophysics, 112, 293-209, 1985.

Hirata, N. and M. Matsu'ura, Maximum-likelihood estimation of hypocenter with origin time eliminated using nonliear inversion technique, Phys. Earth Planet. Inter., 47, 50-61, 1987.

Iwasaki, T., H. Shiobara, A. Nishizawa, T. Kanazawa, K. Suyehiro, N. Hirata, T. Urabe, and H. Shimamura, A detailed subduction structure in the Kuril trench deduced from ocean bottom seismographic refraction studies, Tectonophysics, 165, 315-336, 1989.

Obana, K., S. Kodaira, K. Mochizuki, and M. Shinohara, Micro-seismicity around the seaward updip limit of the 1946 Nankai earthquake dislocation area, Geophys. Res. Lett., 28, 2333-2336, 2001.

Urabe, T., K. Suyehiro, T. Iwasaki, N. Hirata, T. Kanazawa, A. Nishizawa, and H. Shimamura, Aftershock distribution of the 1983 Japan Sea earthquake as determined from helicopter-dispatched OBS observation, $J$. Phys. Earth, 33, 133-147, 1985.

Urabe, T. and S. Tsukada, A workstation-assisted processing system for waveform data from microearthquake networks, Abstracts of Spring Meeting of Seismological Society of Japan, 70 , 1991 (in Japanese).

Watanabe, H., Determination of earthquake magnitude at regional distance in and near Japan, Zisin 2, 24, 189-200, 1971.

Wessel, P. and W. H. F. Smith, New version of the generic mapping tools released, Eos Trans. AGU,

Yamanaka, Y. and M. Kikuchi, Source processes of the recurrent Tokachioki earthquake on September 26, 2003, inferred from teleseismic body waves, Earth Planets Space, 55, e21-e24, 2003.

Yamanaka, Y. and M. Kikuchi, Asperity map along the subduction zone in northeastern Japan inferred from regional seismic data, J. Geophys. Res., 2004 (in press). 76, 329-336, 1995.

M. Shinohara (e-mail: mshino@eri.u-tokyo.ac.jp), T. Yamada, T. Kanazawa, N. Hirata, Y. Kaneda, T. Takanami, H. Mikada, K. Suyehiro, S. Sakai, T. Watanabe, K. Uehira, Y. Murai, N. Takahashi, M. Nishino, K. Mochizuki, T. Sato, E. Araki, R. Hino, K. Uhira, H. Shiobara, and H. Shimizu 